Article

\title{
Warfarin-Capped Gold Nanoparticles: Synthesis, Cytotoxicity, and Cellular Uptake
}

\author{
Loredana Florina Leopold ${ }^{1}$, Dumitriţa Rugină ${ }^{2}$, Ioana Oprea ${ }^{1}$, Zorița Diaconeasa ${ }^{1} \mathbb{D}$, \\ Nicolae Leopold ${ }^{3}{ }^{(0}$, Maria Suciu ${ }^{4,5}$, Vasile Coman ${ }^{6}{ }^{(}$, Dan Cristian Vodnar $\left.{ }^{1}{ }^{(}\right)$, Adela Pintea ${ }^{2}$ \\ and Cristina Coman $1, * \mathbb{B}$
}

1 Faculty of Food Science and Technology, University of Agricultural Sciences and Veterinary Medicine, Mănăștur 3-5, 400372 Cluj-Napoca, Romania; loredana.leopold@usamvcluj.ro (L.F.L.); ioana.oprea@usamvcluj.ro (I.O.); zorita.sconta@usamvcluj.ro (Z.D.); dan.vodnar@usamvcluj.ro (D.C.V.)

2 Faculty of Veterinary Medicine, University of Agricultural Sciences and Veterinary Medicine, Mănăștur 3-5, 400372 Cluj-Napoca, Romania; dumitrita.rugina@usamvcluj.ro (D.R.); apintea@usamvcluj.ro (A.P.)

3 Faculty of Physics, Babeș-Bolyai University, Kogălniceanu 1, 400084 Cluj-Napoca, Romania; nicolae.leopold@phys.ubbcluj.ro

4 Electron Microscopy Center, Faculty of Biology and Geology, Babeș-Bolyai University, Clinicilor 5-7, 400006 Cluj-Napoca, Romania; maria.suciu@itim-cj.ro

5 National Institute for Research and Development of Isotopic and Molecular Technologies, Donath 67-103, 400293 Cluj-Napoca, Romania

6 Institute of Life Sciences, University of Agricultural Sciences and Veterinary Medicine, Mănăstur 3-5, 400372 Cluj-Napoca, Romania; vasile.coman@usamvcluj.ro

* Correspondence: cristina.coman@usamvcluj.ro; Tel.: +40-746-959-157

Received: 5 September 2019; Accepted: 13 November 2019; Published: 15 November 2019

\begin{abstract}
Currently, research studies on nanoparticle cytotoxicity, uptake or internalization into the body's cells are of great interest for the improvement of diagnostic and therapeutic applications. We report here the synthesis and characterization of very stable novel warfarin-capped gold nanoparticles with an average diameter of $54 \pm 10 \mathrm{~nm}$ which were prepared using sodium warfarin as a reducing agent. The nanoparticles were tested in terms of cytotoxicity and cellular internalization in vitro on two cell lines: normal lung fibroblast HFL-1 and human retinal pigment epithelial D407 cells. Our results showed that the normal lung fibroblast HFL-1 cells were more sensitive to the nanoparticle treatment compared to the human retinal pigment epithelial D407 cells. Moreover, any signs of potential cytotoxicity occurred during the first $24 \mathrm{~h}$ of treatment, the cellular viability remaining largely unchanged for longer exposure times. Transmission electron microscopy and dark field hyperspectral imaging revealed that the nanoparticles were effectively delivered and released to the HFL-1 and D407 cells' cytoplasm. Our results provide valuable information to further investigate sodium warfarin-capped gold nanoparticles for possible biological applications.
\end{abstract}

Keywords: gold nanoparticles; D407 cells; HFL-1 cells; internalization

\section{Introduction}

The high interest in metal nanoparticles stems from their quantum scale dimensions, generally below $100 \mathrm{~nm}$, that lead to unique electronic, optical, and magnetic properties and thus their various applications in the biomedical, nanobiotechnology, materials science, chemistry, and physics fields [1,2]. As a consequence of their unique properties, gold nanoparticles (AuNPs) find multiple applications in nanomedicine including diagnostics and imaging [3-5], drug therapy, gene delivery, photothermal cancer therapy [6-15], and the newly developed field of theranostics [16,17]. 
Gold nanoparticles can be synthesized in a large variety of shapes and sizes. Their electronic, optical, and chemical properties are strongly affected by their size, shape, degree of aggregation, and surface chemistry [4,18-20], aspects that can also influence their cellular uptake and cytotoxicity. As opposed to bulk gold, which is essentially inert, higher reactivity can arise at the nanoscale and, therefore, possible associated health and toxicity risks as well. Despite the continuously increasing number of studies focusing on the in vitro and in vivo toxicity assessment of AuNPs, there is still concern and uncertainty regarding their safety and toxicity $[6,21]$.

Several methods have been reported for the synthesis of AuNPs [22]. The most common protocols are based on sodium citrate [23] and sodium borohydride reduction [24], leading to spherical AuNPs with diameters between 10 and $150 \mathrm{~nm}$. Seeding is specially used for obtaining anisotropic particles [25-27]. Many other preparation methods have been reported for the synthesis of colloidal gold, using various reducers [4,28-31], which generate particles with various geometries and sizes. Understanding the nanoparticles' biocompatibility and internalization in cells is of great interest for diagnostics and therapy.

Here, we report the synthesis of AuNPs capped with warfarin (a well-known anticoagulant) [32], their cytotoxicity, and internalization in two normal cell lines: human fetal lung fibroblast (HFL-1) and human retinal pigment epithelial (D407) cells. The obtained AuNPs had a polygonal shape, mean size of $54 \pm 10 \mathrm{~nm}$ measured with transmission electron microscopy (TEM), and showed characteristic surface plasmon resonance bands at $540 \mathrm{~nm}$. The cellular internalization was investigated by TEM for both cell lines and by dark field hyperspectral imaging for the D407 cells. The gold nanoparticles were able to cross the cellular membrane and were mainly localized in lysosomes or free in the cell cytoplasm. According to MTT viability assays, the normal lung fibroblast HFL-1 cells were more sensitive to the warfarin-capped AuNPs treatment compared to the human retinal pigment epithelial D407 cells and any potential cytotoxicity occurred during the first $24 \mathrm{~h}$ of treatment.

\section{Results and Discussion}

\subsection{AuNPs Characterization}

The reduction of the $\mathrm{HAuCl}_{4}$ salt and the formation of the AuNPs were confirmed by UV-Vis spectroscopy measurements (Figure 1).

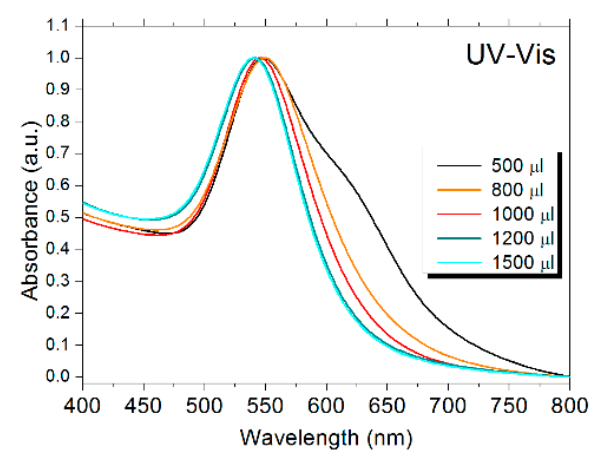

Figure 1. Normalized UV-Vis absorption spectra of the AuNPs obtained by reducing the $\mathrm{HAuCl}_{4}$ salt with different amounts of $1 \%$ aqueous warfarin solution.

Addition of $1 \%$ warfarin solution to the gold salt created changes in color, from colorless to different tones of pink purple. The color of the colloidal AuNPs solutions and the wavelength of the surface plasmon resonance peak depends on the nanoparticles size, geometry, and monodispersity of the samples [6]. The wavelength of the surface plasmon resonance peaks decreased with an increase in the amount of warfarin in the reduction process. The lowest wavelength of the surface plasmon resonance peaks implied the smallest nanoparticle size as the reduction process became complete. The reason for the shoulder at approximately $625 \mathrm{~nm}$ when adding low warfarin amounts $(500 \mu \mathrm{L})$ 
was that the reduction process of $\mathrm{Au}^{+3}$ was far from being completed and the nanoparticles were probably more anisotropic and not uniform in shape. The appearance of the shoulder in the plasmonic band right after the synthesis started (addition of warfarin) was not surprising. Todor et al. (2014) [33] observed a more pronounced shift of the plasmonic band during the synthesis process. At saturation, narrow peaks were obtained with absorption maxima at $540 \mathrm{~nm}$. This was basically the point where enough excess of the reducing agent was added so that the Au was totally reduced, and the appearance of the UV-Vis spectra did not change with the increase in the amount of reducing agent.

A representative TEM image of the AuNPs is shown in Figure 2a. The image shows polygonal nanoparticles, predominantly hexagonal and with a mean size of $54 \pm 10 \mathrm{~nm}$. Our values were very close to the previously reported ones, and the slight difference in absorbance most likely came from the polygonal geometry of the warfarin-reduced AuNPs compared to the citrate-reduced ones reported by Haiss et al. [34]. The size distribution histogram of the AuNPs, as obtained from the analysis of the TEM micrographs, is illustrated in Figure 2c, showing size variations in the 43-65 nm range. Elemental analysis was also performed by energy-dispersive spectroscopy (EDS). The characteristic spectrum of the nanoparticles is shown in Figure $2 \mathrm{~b}$. The characteristic peaks prove the presence of elemental $\mathrm{Au}$ in the samples, as well as $\mathrm{C}$ and $\mathrm{O}$ which were expected due to the presence of the warfarin capping layer onto the nanoparticle surface.

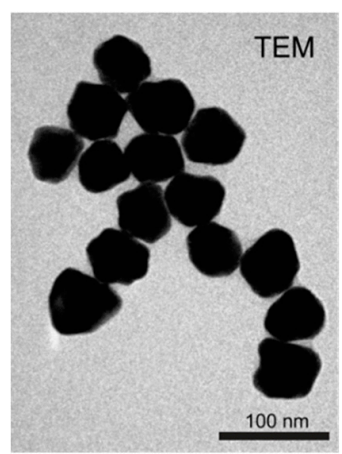

(a)

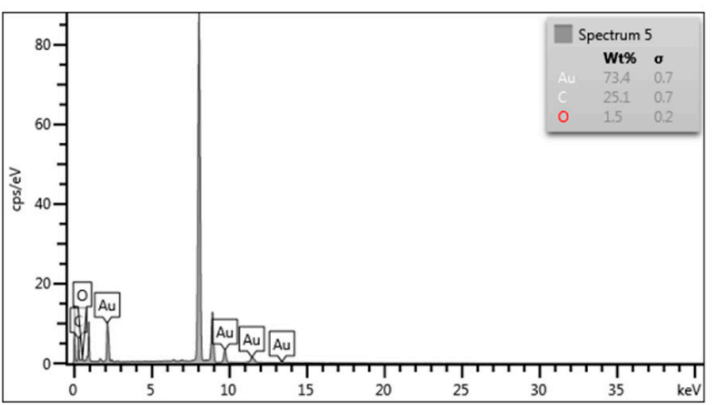

(b)

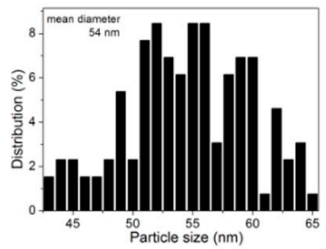

(c)

Figure 2. (a) TEM micrographs of the colloidal AuNPs (scale bar $100 \mathrm{~nm}$ ); (b) EDS spectrum of the AuNPs; (c) particle size distribution from TEM.

Since the stability of a colloidal solution is related to the surface charge of the particles, the stability of the prepared colloidal nanoparticle solution was assessed by zeta potential measurements. The measured zeta potential of the AuNPs was $-37.7 \pm 4.1 \mathrm{mV}$. This indicates the presence of negatively charged particles with good stability due to the electrostatic repulsions among the nanoparticles. Another proof of nanoparticle stability comes from the analysis of the UV-Vis spectra in time, at one week and one month post-synthesis (Figure 3). The appearance of the spectra was very similar, proving, once again, good stability.

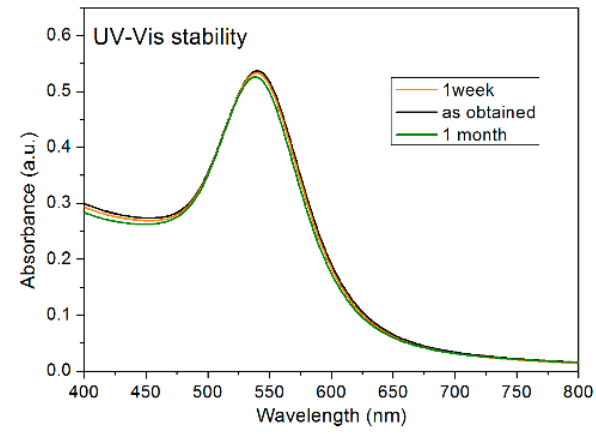

Figure 3. UV-Vis spectra of the AuNPs after one week and one month from the synthesis process. 
Figure 4 shows typical FTIR spectra for the colloidal AuNPs (bottom spectrum) and for an aqueous $1 \%$ warfarin solution (upper spectrum). Prior to the FTIR experiments, the colloidal samples were centrifuged and washed three times to remove excess reagents. The spectra showed the same characteristic peaks, indicating that the nanoparticles were capped with warfarin, being thus both the reducing and capping agent. The stretching vibrations of the two $\mathrm{C}=\mathrm{O}$ bonds of warfarin were observed as a large band at $1701 \mathrm{~cm}^{-1}$. The bands at $1597 \mathrm{~cm}^{-1}$ and $1506 \mathrm{~cm}^{-1}$ can be assigned to $C=C$ stretching in the warfarin solution. The asymmetric and symmetric bending vibrations of the $\mathrm{CH}_{3}$ group were observed at $1449 \mathrm{~cm}^{-1}$ and $1350 \mathrm{~cm}^{-1}$, respectively. Further, the out-of-plane bending vibrations of $\mathrm{C}-\mathrm{H}$ of the phenyl rings were observed at $899 \mathrm{~cm}^{-1}, 756 \mathrm{~cm}^{-1}$, and $700 \mathrm{~cm}^{-1}$. The band at $1223 \mathrm{~cm}^{-1}$ can be assigned to the hemiketal ring in-plane bending vibration. For the nanoparticles capped with warfarin, vibrational bands with lower intensities compared to the warfarin reference spectrum were observed.

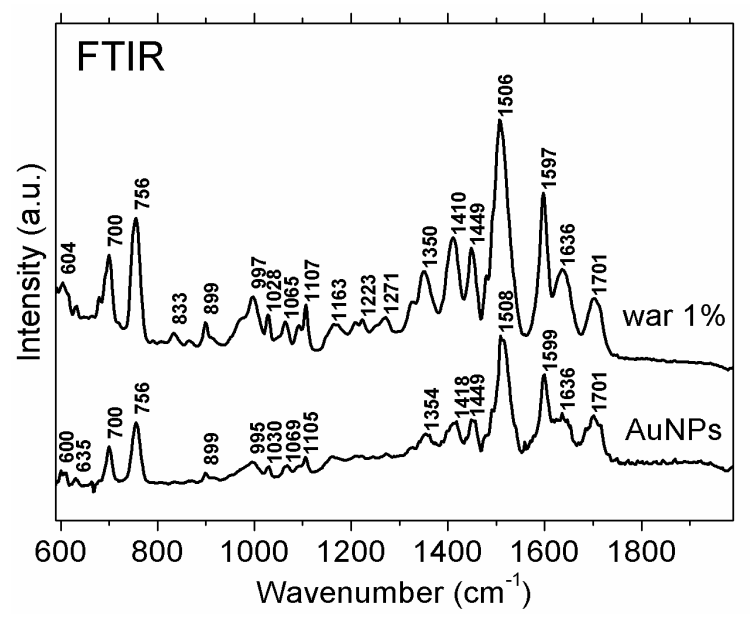

Figure 4. FTIR spectra of the colloidal AuNPs obtained by reducing the $\mathrm{HAuCl}_{4}$ salt with warfarin (bottom spectrum) and a 1\% warfarin solution in water (upper spectrum).

\subsection{Cytotoxicity and Cellular Uptake}

Toxicity experiments were performed using HFL-1 and D407 cell lines after incubation with warfarin-capped gold nanoparticles for $24 \mathrm{~h}$ and $48 \mathrm{~h}$ in complete DMEM at different particle concentrations (up to $150 \times 10^{-13} \mathrm{M}$ ). For the whole concentration range tested, no significant changes in cell survival rate were observed by increasing the exposure time to nanoparticles from 24 to $48 \mathrm{~h}$, indicating that any potential cytotoxic effects are expected to be observed at a maximum within the first $24 \mathrm{~h}$ of exposure, more likely during the first hours. Independent of the duration of the nanoparticle treatment, nanoparticles administered in lower concentrations $\left(0-37.5 \times 10^{-13} \mathrm{M}\right)$ did not have any significant deviation from the control (untreated cells with completed DMEM). However, when administrating higher concentrations, a dose-dependent reduction was observed, and it must be noted that HFL-1 proved to be more sensitive than the D407 cell line (Figure 5). The survival rate in both cases was reduced to a maximum $20 \%$ for D 407 cells and $40 \%$ for HFL cell line, respectively. 
(A).

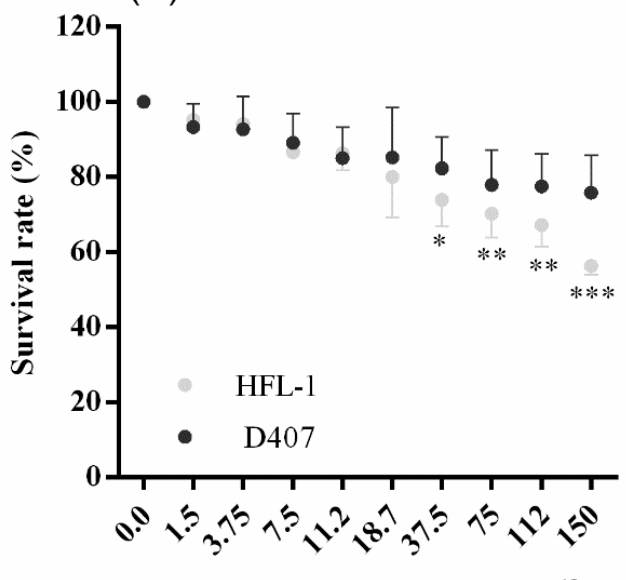

Nanoparticle concentration $\left(* 10^{-13} \mathrm{M}\right)$
(B).

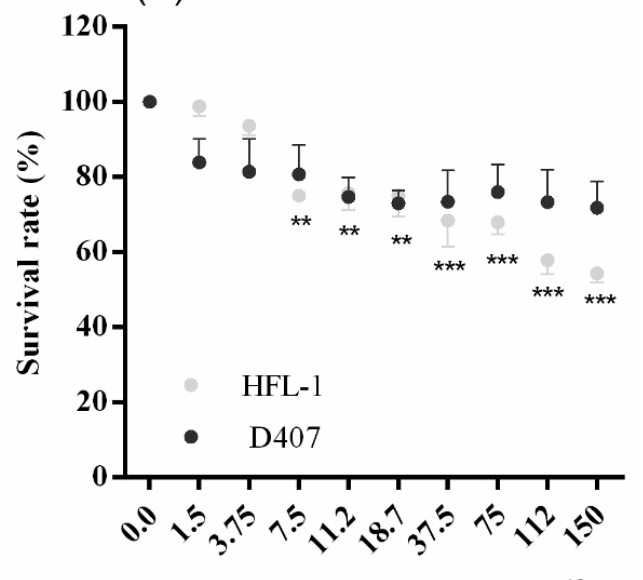

Nanoparticle concentration $\left(* 10^{-13} \mathrm{M}\right)$

Figure 5. Cell viability assessed by MTT assay (mean $\pm \mathrm{SD} ; n=3$ ). The AuNPs' effect on the survival rate of HFL-1 and D407 cells after $24 \mathrm{~h}(\mathbf{A})$ and $48 \mathrm{~h}$ (B) of treatment. Statistically significant differences: $(*=$ significant, $p$-value range $0.01-0.05, * *=$ very significant, $p$-value range $0.001-0.01$, and $* * *=$ extremely significant, $p<0.001)$.

\subsection{Internalization and Cellular Localization of AuNPs}

The warfarin-capped gold nanoparticles were successfully internalized into HFL-1 and D407 cells as observed on microtome sections analyzed by TEM (Figure 6).
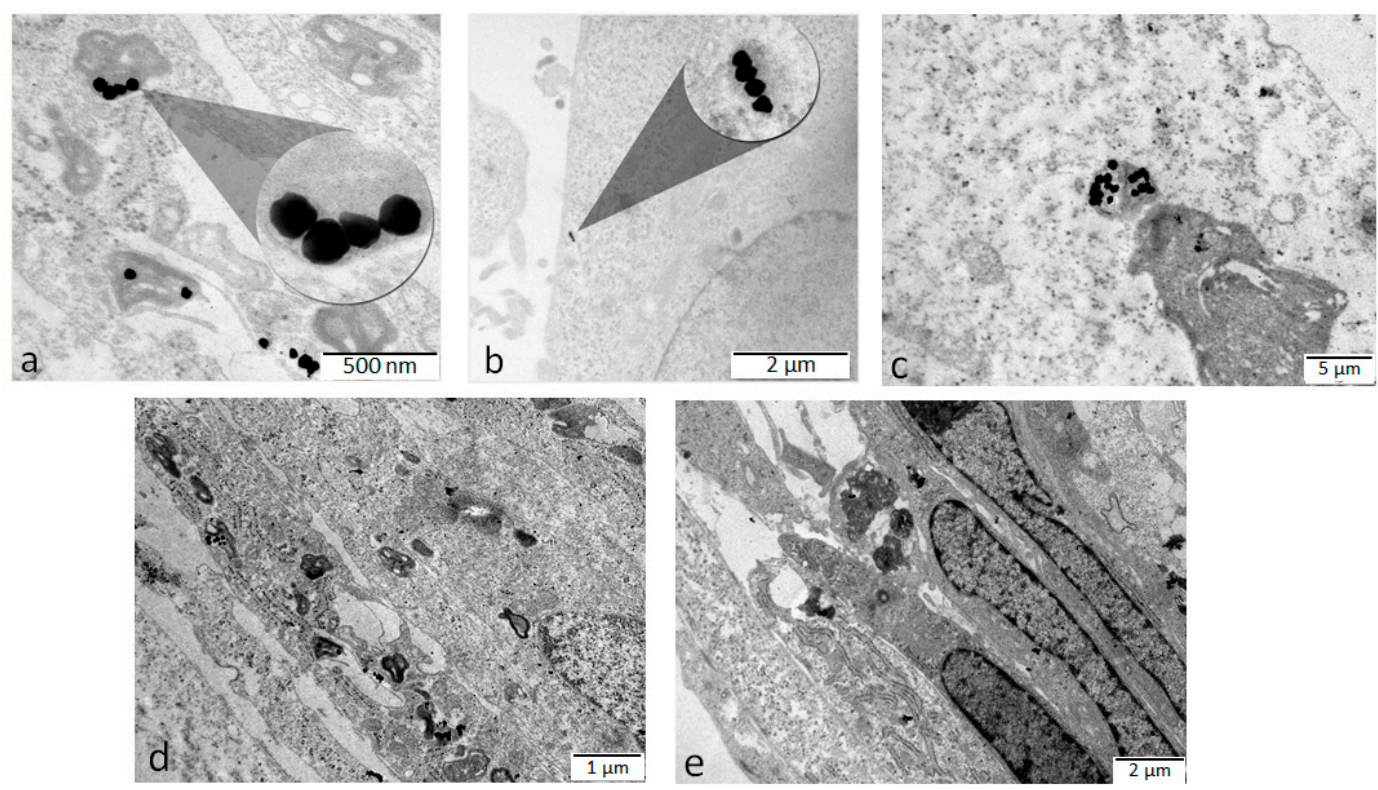

Figure 6. TEM micrographs obtained from (a,d,e) HFL-1 and (b,c) D407 cells treated by $75 \times 10^{-13} \mathrm{M}$ AuNPs for $24 \mathrm{~h}$. The images show the intracellular distribution of the AuNPs in the cells. All the observed intracellular AuNPs were either clustered inside lysosomes or cytosol compartments. Scale bars: (a) $500 \mathrm{~nm},($ b) $2 \mu \mathrm{m}$, (c) $5 \mu \mathrm{m}$, (d) $1 \mu \mathrm{m}$, (e) $2 \mu \mathrm{m}$.

Transmission electron microscopyoffers a very high spatial resolution owing to the small de Broglie wavelength of electrons [35]. On both cell lines, internalized warfarin-capped gold nanoparticles were visible as densely packed clusters confined in myelinic-like lysosomes. Also, electron-dense areas of AuNPs located in the cell cytoplasm were observed, indicating the presence of non-entrapped, isolated nanoparticles. These nanoparticles were not included in endosomal/lysosomal vesicles and 
were rather free in the cytoplasm. Most probably, the internalization mechanism was an endocytic one, in which nanoparticles were enclosed in endosomes, then fused into lysosomes, and, finally, some of the particles were released in the cytosol [36]. This last situation is the most desirable for potential drug delivery systems based on gold nanoparticles. The main limitation of the delivery techniques based on nanoparticles described so far is the ultimate vesicular localization [19,21,37-39] of nanoparticles and their unavailability in the cytosol or in the cell nucleus as free particles ready to exert their desired health effects. As other studies report [37,40,41], most of these nanoparticles have the tendency to aggregate in clusters inside cells, which is also the case here. As seen from the lower magnification TEM micrographs in Figure $6 \mathrm{~d}, \mathrm{e}$, the HFL-1 cells were 5-7 $\mu \mathrm{m}$ long cells, with elongated nuclei, one large electron-dense nucleolus, and an extensive endoplasmic reticulum. Ribosomes can clearly be seen aligned along the endoplasmic reticulum and spread in the cytoplasm.

\subsection{CytoViva Enhanced Dark Field Hyperspectral Imaging}

Thanks to its unique, patented illumination optics, darkfield hyperspectral imaging provides detailed maps of surface plasmon resonance spectra for every pixel. It is possible to image nanoparticles in cells with very good resolution. Another great advantage of the system is that large surface areas corresponding to large numbers of cells can be investigated in a short time as opposed to TEM which requires time-consuming embedding and sectioning steps.

The CytoViva enhanced dark field hyperspectral imaging instrument combines dark field microscopy with NIR-Vis hyperspectral imaging, making it possible to obtain optical imaging and spectral characterization of nanoparticle samples present in biological environments such as cells and tissues $[42,43]$. The system does not require the use of any fluorescent labels, and the resolution can go down to $2 \mathrm{~nm}$.

Figure 7a is an enhanced darkfield hyperspectral image of a control D407 sample. The darker areas represent the nuclei of the cells, while the bright spots represent endosomes within the D407 cells. In Figure $7 \mathrm{~b}$, an enhanced dark field hyperspectral image of D407 cells treated with AuNPs $\left(75 \times 10^{-13} \mathrm{M}\right)$ is shown. The AuNPs cause a different spectral response in areas where they are present in the cell cytoplasm. A comparison between the spectral fingerprint of warfarin-capped nanoparticles in cells (red) and the spectral response of the D407 cells (white) is shown in Figure 7c. The differences in the spectral fingerprint of the warfarin-capped nanoparticles and cells allows a spectral mapping of the sample, making it possible to distinguish the warfarin-capped nanoparticles inside cells. In Figure $7 \mathrm{~d}$, the AuNPs spectra are mapped in the D407 cells. The pixel areas representative for the AuNPs in the cells are shown in red in order to clearly distinguish their presence in the D407 cell cytoplasm. The AuNPs were mostly present as aggregates, but areas of dispersed nanoparticles were also present as well. 


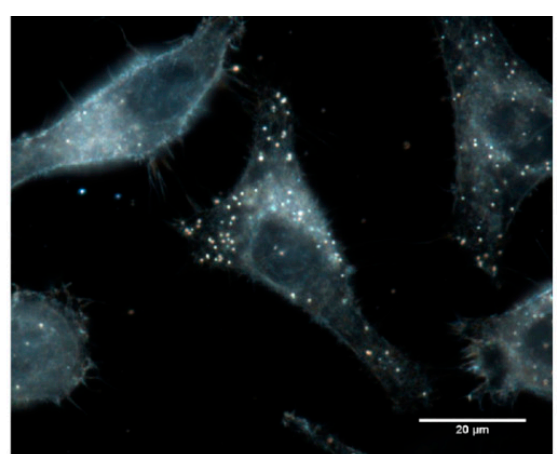

a

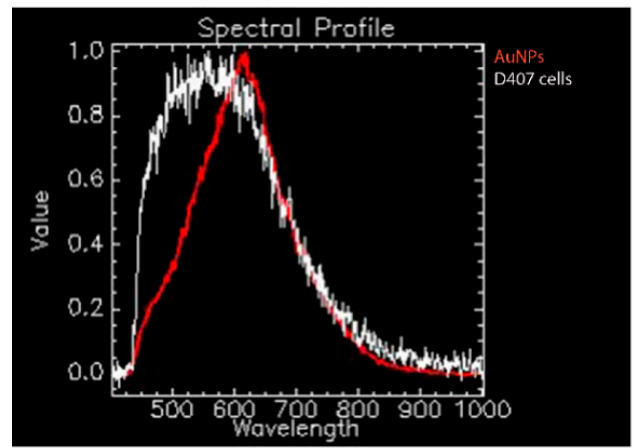

C

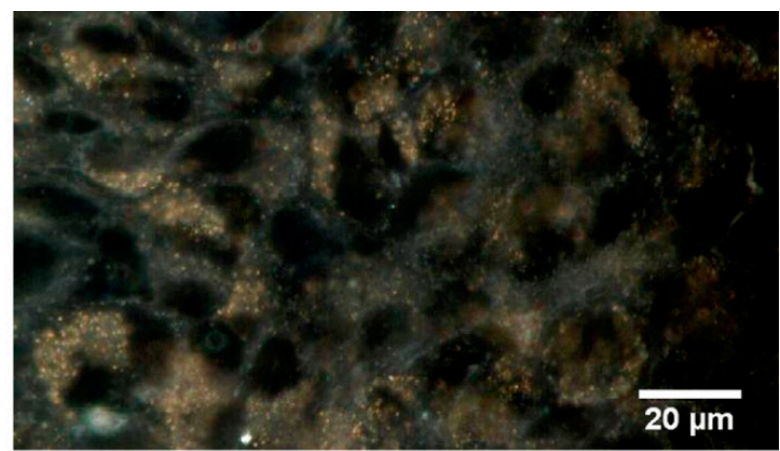

b

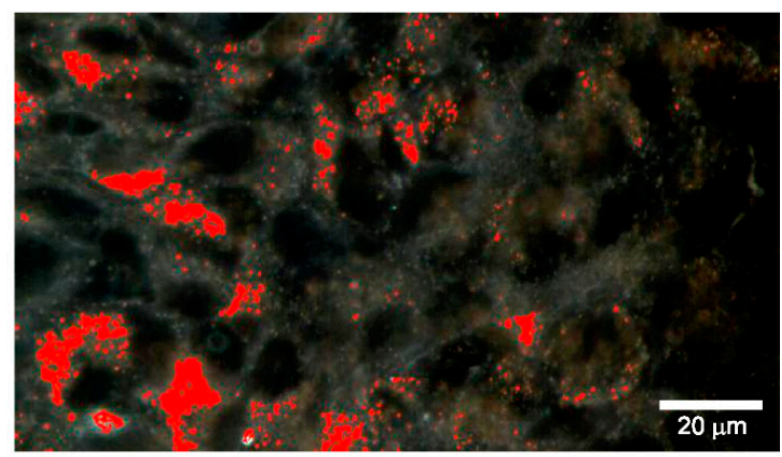

d

Figure 7. (a) Enhanced dark field hyperspectral images of control D407 cells. Scale bar: $20 \mathrm{~nm}$, magnification 100×. (b) Hyperspectral image of AuNPs within D407 cells; (c) spectral profile of AuNPs and D407 cells; (d) AuNP spectra (red) mapped in D407 cells.

\section{Materials and Methods}

\subsection{Chemicals and Materials}

Hydrogen tetrachloroaurate(III) $\left(\mathrm{HAuCl}_{4} * 4 \mathrm{H}_{2} \mathrm{O}\right)$ was purchased from Merck (Darmstadt, Germany). Warfarin sodium (3-( $\alpha$-Acetonylbenzyl)-4-hydroxycoumarin sodium salt) was purchased from Aldrich (St Louis, MO, USA). Dulbecco's modified Eagle's medium (DMEM), fetal bovine serum (FBS), and 3-(4,5-dimethylthiazol-2-yl)-2,5-diphenyltetrazolium bromide (MTT) were purchased from Lonza Group Ltd. (Basel, Switzerland). Kaighn's Modification of Ham's F-12 Medium was purchased from GIBCO (Cralsbad, CA, USA). The mixture of penicillin and streptomycin was purchased from Sigma Chemical Co. (St. Louis, MO, USA). Glutaraldehyde, OsO4, Epon 812 resin, and copper grids were purchased from Agar Sientific (Essex, UK); phosphate buffer components and acetone were purchased from Sigma.

\subsection{Cell Cultures}

The human fetal lung fibroblast HFL-1 cell line was purchased from American Type Culture Collection (ATCC) (Manassas, VA, USA). According to the ATCC's recommendation, it was maintained in Kaighn's Modification of Ham's F-12 Medium (F-12K) with fetal bovine serum (10\%), glutamine $(200 \mathrm{mM})$, and antibiotics (1\%). The human retinal epithelial D407 cell line was kindly donated by Horst A. Diehl, University of Bremen. The D407 cells were cultured in high glucose DMEM, containing fetal bovine serum $(10 \%)$, glutamine $(200 \mathrm{mM})$, and antibiotics $(1 \%)$. Both cell lines were maintained and cultivated in standard conditions of $37{ }^{\circ} \mathrm{C}, 5 \% \mathrm{CO}_{2}$, and a relative humidity of $95 \%$. 


\subsection{Nanoparticle Synthesis}

For the synthesis of AuNPs, different amounts of warfarin 1\% solution $(500-1500 \mu \mathrm{L})$ were added to $50 \mathrm{~mL}$ of $0.1 \mathrm{mM} \mathrm{HAuCl} 4$ at boiling and the solution was further boiled for $5 \mathrm{~min}$. The protocol resulted in the formation of purple-red colloidal solutions with $\mathrm{pH} 8$.

\subsection{Characterization Methods and Zeta Potential}

The UV-Vis spectra of the AuNP colloidal solutions were recorded on a Perkin Elmer Lambda 25 spectrometer (Perkin Elmer, Waltham, MA, USA) using $1 \mathrm{~cm}$ path length quartz cuvettes. The spectral resolution was $1 \mathrm{~nm}$, and the spectra were recorded at 400-800 $\mathrm{nm}$. The FTIR spectra were recorded in the attenuated total reflectance (FTIR-ATR) mode using a Shimadzu IR-Prestige FTIR Spectrometer (Schimadzu, Tokio, Japan) equipped with a diamond PIKE MIRacle single-reflection plate unit. The measurements were performed with a resolution of $4 \mathrm{~cm}^{-1}$ in the wavenumber range of $600-4000 \mathrm{~cm}^{-1}$, and each spectrum was obtained by co-addition of 64 interferograms. For the FTIR-ATR spectra recordings, drops of colloidal AuNP solution were placed on the ATR plate and dried. For removal of excess reagents from the synthesis process, the as-obtained samples were centrifuged three times at 13,000 RPM for $10 \mathrm{~min}$.

The TEM experiments were carried out using a JEOL model JEM1010 (Jeol, Peabody, MA, USA) transmission electron microscope equipped with a MegaViewIII CCD camera, operating at $100 \mathrm{kV}$ accelerating voltage. For the morphology characterization of the nanoparticles, a drop of colloidal AuNP solution was placed onto a copper grid and allowed to dry. The average size of the AuNPs was estimated using the ImageJ software (version 1.46, national Institues of Health - NIH, Bethesda, MD, USA).

The zeta potential was measured using a Malvern Zetasizer Nano ZS equipped with a $4 \mathrm{~mW} \mathrm{He}-\mathrm{Ne}$ laser operating at $633 \mathrm{~nm}$ and an avalanche photodiode detector (Malvern Instruments, Worcestershire UK). Zeta potential was measured by laser Doppler electrophoresis. Three replicate measurements were carried out at $25^{\circ} \mathrm{C}$.

\subsection{Cellular Internalization}

\subsubsection{TEM}

For visualization of cellular internalization by TEM, cells HFL-1 $\left(1 \times 10^{3} /\right.$ well $)$ and D407 $\left(8 \times 10^{3} /\right.$ well) were seeded for $24 \mathrm{~h}$ on Falcon cell culture inserts $(0.4 \mu \mathrm{m})$ (Becton Dickinson Labware, $\mathrm{NJ}$, USA). Afterwards, the cells were incubated for another $24 \mathrm{~h}$ with $75 \times 10^{-13} \mathrm{M}$ AuNPs. The culture medium was then removed, and the cells were washed three times with phosphate buffer saline (PBS) and prefixed for $1 \mathrm{~h}$ with glutaraldehyde (2.5\% in PBS). Next, the three steps of rinsing with PBS and cells were post-fixed for $1 \mathrm{~h}$ in osmium tetroxide (2\% in PBS). Dehydration was carried out in HPLC grade acetone in distilled water dilutions, followed by embedding with Epon resin. The resin was polymerized at $60{ }^{\circ} \mathrm{C}$ for $48 \mathrm{~h}$ then cooled for $12 \mathrm{~h}$. Ultra-thin sections of approximately $70 \mathrm{~nm}$, obtained on a diamond knife (Diatome) with Leica UC6 ultramicrotome, were post-stained with lead citrate and uranyl acetate [35]. Sections collected on 200 mesh $\mathrm{Cu}$ grids were examined with TEM.

\subsubsection{CytoViva Dark Field Hyperspectral Imaging}

The D407 and HFL- 1 cells $\left(8 \times 10^{4}\right.$ cells/chamber) were seeded on sterile glass slides for $24 \mathrm{~h}$. Next, $75 \times 10^{-13} \mathrm{M}$ AuNPs were applied on both cell lines for another $24 \mathrm{~h}$. After that, the fixation procedure was carried out after three PBS washing steps by incubating cells with $4 \%$ paraformaldehyde for $20 \mathrm{~min}$ at room temperature. Cells without nanoparticle treatment were used as control. A CytoViva Enhanced Dark Field Hyperspectral Microscope (CytoViva Inc., Auburn, AL, USA) mounted on an Olympus BX-43 optical microscope was used to image the treated and non-treated D407 and HFL-1 cells. The system contains a patented illumination optics that improves up to 10 times the signal-to-noise 
ratio, making it possible to visualize nanoparticles (down to $\sim 10 \mathrm{~nm}$ ). The images were taken using the $100 \times$ and $60 \times$ (UPL Fluorite) oil immersion objectives.

\subsection{Cytotoxicity Assay}

Cell viability was measured by the MTT assay. The MTT detection principle is based on the reduction of the MTT reagent to colored formazan by mitochondrial and cytosol dehydrogenases, which can be detected by measuring its absorbance at $550 \mathrm{~nm}$. The HFL-1 and D407 cells were seeded separately in 96 well plates at a concentration of $5 \times 10^{3} /$ well and $8 \times 10^{3} /$ well, respectively. After $24 \mathrm{~h}$ from seeding, the cells were treated with different nanoparticle concentrations $\left(1.5-150 \times 10^{-13} \mathrm{M}\right)$. Cell viability was monitored $24 \mathrm{~h}$ and $48 \mathrm{~h}$ post-treatment. Briefly, cells were washed with PBS and then incubated with MTT $(0.5 \mathrm{mg} / \mathrm{mL})$ for $1 \mathrm{~h}$. After that the formazan crystals were solubilized in dimethyl sulfoxide (DMSO), their absorbance was monitored at $550 \mathrm{~nm}$ and $630 \mathrm{~nm}$ (for the background) using the microplate reader HT BioTek Synergy (BioTek Instruments, USA). The results were expressed as the survival rate compared to control. Each experiment was repeated three times.

\subsection{Statistical Analysis}

Statistical analysis was performed using the Duncan multiple comparison test in GraphPad Prism version 5.00. Registered data represented the mean values and standard deviations (SDs) of three experiments (ns $=$ not significant, $p \geq 0.05, *=$ significant, $p$-value $0.01-0.05, * *=$ very significant, $p$-value $0.001-0.01$, and $* * *=$ extremely significant, $p<0.001$ ).

\section{Conclusions}

In this study we obtained stable, polygonal-shaped AuNPs using sodium warfarin. The AuNPs were able to cross the cellular membrane of the HFL-1 and D407 cells. After entering the cells, the nanoparticles were visualized being localized in the cytoplasm, mainly in lysosome compartments; however, free nanoparticles were also present. A dose-dependent reduction in cell viability was observed upon exposure to higher concentrations of warfarin-capped nanoparticles in both D407 and HFL-1 cells. The survival rate was reduced by a maximum $20 \%$ for D 407 cells and $40 \%$ for the HFL cell line. It must be noted that HFL-1 proved to be more sensitive than the D407 cell line to the warfarin-capped nanoparticle treatment. Also, exposing the cells to nanoparticles for $48 \mathrm{~h}$ did not induce any significant changes in the cell survival rate compared to the $24 \mathrm{~h}$ exposure. By using the dark field hyperspectral imaging, it was possible to image the warfarin-capped nanoparticles' location in cells and to obtain, at the same time, spectral confirmation of their presence. The obtained nanoparticles may be of interest for potential biological applications.

Author Contributions: C.C. conceived and designed the experiments and wrote the first draft of the manuscript; D.R. performed the cytotoxicity experiments and contributed to manuscript writing; I.O. was involved in the synthesis of gold nanoparticles and sample preparations for hyperspectral imaging; Z.D. was involved in the cell culture experiments; N.L. provided support for the DLS and Hyperspectral Imaging; M.S. performed the TEM analysis; V.C. performed the UV-Vis experiments and critically revised the manuscript; D.C.V. provided support for data analysis; A.P. provided scientific support and resources for the cell culture experiments; L.F.L. performed UV-Vis, FTIR experiments and supervised the experimental work. All authors reviewed the manuscript and approved it for submission to the journal in its current form.

Funding: This work was supported by a grant from the Ministry of Research and Innovation, CNCS - UEFISCDI, project number PN-III-P1-1.1-TE-2016-1907, within PNCDI III. The publication was supported by funds from the National Research Development Project to Finance Excellence, (PFE)-37/2018-2020, granted by the Romanian Ministry of Research and Innovation.

Acknowledgments: The authors are grateful to CytoViva Inc., who made it possible to record the data during an experimental demonstration workshop in Cluj-Napoca, Romania.

Conflicts of Interest: The authors declare no conflict of interest. The funders had no role in the design of the study; in the collection, analyses, or interpretation of data; in the writing of the manuscript, or in the decision to publish the results. 


\section{References}

1. Daniel, M.C.; Astruc, D. Gold nanoparticles: Assembly, supramolecular chemistry, quantum-size-related properties, and applications toward biology, catalysis, and nanotechnology. Chem. Rev. 2004, 104, $293-346$. [CrossRef] [PubMed]

2. Giljohann, D.A.; Seferos, D.S.; Daniel, W.L.; Massich, M.D.; Patel, P.C.; Mirkin, C.A. Gold nanoparticles for biology and medicine. Angew. Chem. Int. Ed. 2010, 49, 3280-3294. [CrossRef] [PubMed]

3. Boisselier, E.; Astruc, D. Gold nanoparticles in nanomedicine: Preparations, imaging, diagnostics, therapies and toxicity. Chem. Soc. Rev. 2009, 38, 1759-1782. [CrossRef] [PubMed]

4. Dreaden, E.C.; Alkilany, A.M.; Huang, X.; Murphy, C.J.; El-Sayed, M.A. The golden age: Gold nanoparticles for biomedicine. Chem. Soc. Rev. 2012, 41, 2740-2779. [CrossRef]

5. Zhou, W.; Gao, X.; Liu, D.; Chen, X. Gold nanoparticles for in vitro diagnostics. Chem. Rev. 2015, 115, 10575-10636. [CrossRef]

6. Alkilany, A.M.; Murphy, C.J. Toxicity and cellular uptake of gold nanoparticles: What we have learned so far? J. Nanoparticle Res. 2010, 12, 2313-2333. [CrossRef]

7. Cherukuri, P.; Glazer, E.S.; Curley, S.A. Targeted hyperthermia using metal nanoparticles. Adv. Drug Deliv. Rev. 2010, 62, 339-345. [CrossRef]

8. Davis, M.E.; Chen, Z.; Shin, D.M. Nanoparticle therapeutics: An emerging treatment modality for cancer. Nat. Rev. Drug Discov. 2008, 7, 771-782. [CrossRef]

9. De Jong, W.H.; Borm, P.J.A. Drug delivery and nanoparticles: Applications and hazards. Int. J. Nanomed. 2008, 3, 133-149. [CrossRef]

10. Huang, X.; El-Sayed, M.A. Gold nanoparticles: Optical properties and implementations in cancer diagnosis and photothermal therapy. J. Adv. Res. 2010, 1, 13-28. [CrossRef]

11. Kong, F.Y.; Zhang, J.W.; Li, R.F.; Wang, Z.X.; Wang, W.J.; Wang, W. Unique roles of gold nanoparticles in drug delivery, targeting and imaging applications. Molecules 2017, 22, 13.

12. Pissuwan, D.; Niidome, T.; Cortie, M.B. The forthcoming applications of gold nanoparticles in drug and gene delivery systems. J. Control. Release 2011, 149, 65-71. [CrossRef] [PubMed]

13. Rana, S.; Bajaj, A.; Mout, R.; Rotello, V.M. Monolayer coated gold nanoparticles for delivery applications. Adv. Drug Deliv. Rev. 2012, 64, 200-216. [CrossRef] [PubMed]

14. Wang, C.; Cheng, L.; Liu, Z. Upconversion nanoparticles for photodynamic therapy and other cancer therapeutics. Theranostics 2013, 3, 317-330. [CrossRef] [PubMed]

15. Wicki, A.; Witzigmann, D.; Balasubramanian, V.; Huwyler, J. Nanomedicine in cancer therapy: Challenges, opportunities, and clinical applications. J. Control. Release 2015, 200, 138-157. [CrossRef] [PubMed]

16. Jing, H.; Sinha, S.; Sachar, H.S.; Das, S. Interactions of gold and silica nanoparticles with plasma membranes get distinguished by the van der waals forces: Implications for drug delivery, imaging, and theranostics. Colloids Surf. B Biointerfaces 2019, 177, 433-439. [CrossRef]

17. Xie, J.; Lee, S.; Chen, X. Nanoparticle-based theranostic agents. Adv. Drug Deliv. Rev. 2010, 62, $1064-1079$. [CrossRef]

18. Fu, C.; Yang, H.; Wang, M.; Xiong, H.; Yu, S. Serum albumin adsorbed on au nanoparticles: Structural changes over time induced by s-au interaction. Chemi. Commun. 2015, 51,3634-3636. [CrossRef]

19. Jones, C.F.; Grainger, D.W. In vitro assessments of nanomaterial toxicity. Adv. Drug Deliv. Rev. 2009, 61, 438-456. [CrossRef]

20. Qiu, Y.; Liu, Y.; Wang, L.; Xu, L.; Bai, R.; Ji, Y.; Wu, X.; Zhao, Y.; Li, Y.; Chen, C. Surface chemistry and aspect ratio mediated cellular uptake of au nanorods. Biomaterials 2010, 31, 7606-7619. [CrossRef]

21. Khlebtsov, N.; Dykman, L. Biodistribution and toxicity of engineered gold nanoparticles: A review of in vitro and in vivo studies. Chem. Soc. Rev. 2011, 40, 1647-1671. [CrossRef] [PubMed]

22. Zhao, P.; Li, N.; Astruc, D. State of the art in gold nanoparticle synthesis. Coord. Chem. Rev. 2013, 257, 638-665. [CrossRef]

23. Turkevich, J.; Stevenson, P.C.; Hillier, J. A study of the nucleation and growth processes in the synthesis of colloidal gold. Discuss. Faraday Soc. 1951, 11, 55-75. [CrossRef] 
24. Brust, M.; Walker, M.; Bethell, D.; Schiffrin, D.J.; Whyman, R. Synthesis of thiol-derivatised gold nanoparticles in a two-phase liquid-liquid system. J. Chem. Soc. Chem. Commun. 1994, 801-802. [CrossRef]

25. Li, N.; Zhao, P.; Astruc, D. Anisotropic gold nanoparticles: Synthesis, properties, applications, and toxicity. Angew. Chem. Int. Ed. 2014, 53, 1756-1789. [CrossRef] [PubMed]

26. Murphy, C.J.; Sau, T.K.; Gole, A.M.; Orendorff, C.J.; Gao, J.; Gou, L.; Hunyadi, S.E.; Li, T. Anisotropic metal nanoparticles: Synthesis, assembly, and optical applications. J. Phys. Chem. B 2005, 109, 13857-13870. [CrossRef] [PubMed]

27. Nikoobakht, B.; El-Sayed, M.A. Preparation and growth mechanism of gold nanorods (nrs) using seed-mediated growth method. Chem. Mater. 2003, 15, 1957-1962. [CrossRef]

28. Chithrani, B.D.; Chan, W.C.W. Elucidating the mechanism of cellular uptake and removal of protein-coated gold nanoparticles of different sizes and shapes. Nano Lett. 2007, 7, 1542-1550. [CrossRef]

29. Coman, C.; Leopold, L.F.; Rugină, O.D.; Barbu-Tudoran, L.; Leopold, N.; Tofană, M.; Socaciu, C. Green synthesis of gold nanoparticles by allium sativum extract and their assessment as sers substrate. J. Nanoparticle Res. 2014, 16, 2158. [CrossRef]

30. Leopold, N.; Chiş, V.; Mircescu, N.E.; Marişca, O.T.; Buja, O.M.; Leopold, L.F.; Socaciu, C.; Braicu, C.; Irimie, A.; Berindan-Neagoe, I. One step synthesis of sers active colloidal gold nanoparticles by reduction with polyethylene glycol. Colloids Surf. Physicochem. Eng. Aspects 2013, 436, 133-138. [CrossRef]

31. Narayanan, K.B.; Sakthivel, N. Green synthesis of biogenic metal nanoparticles by terrestrial and aquatic phototrophic and heterotrophic eukaryotes and biocompatible agents. Adv. Colloid Interface Sci. 2011, 169, 59-79. [CrossRef] [PubMed]

32. National Center for Biotechnology Information. Pubchem Database. Warfarin Sodium, cid=16204922. Available online: https://pubchem.Ncbi.Nlm.Nih.Gov/compound/warfarin-sodium (accessed on 24 July 2019).

33. Tódor, I.S.; Szabó, L.; Marişca, O.T.; Chiş, V.; Leopold, N. Gold nanoparticle assemblies of controllable size obtained by hydroxylamine reduction at room temperature. J. Nanopart. Res. 2014, 16, 2740. [CrossRef]

34. Haiss, W.; Thanh, N.T.K.; Aveyard, J.; Fernig, D.G. Determination of size and concentration of gold nanoparticles from uv-vis spectra. Anal. Chem. 2007, 79, 4215-4221. [CrossRef] [PubMed]

35. Hayat, M.A. Basic Techniques for Transmission Electron Microscopy, 1st ed.; Academic Press Inc.: San Diego, CA, USA, 1985; pp. 4-162.

36. Oh, N.; Park, J.H. Endocytosis and exocytosis of nanoparticles in mammalian cells. Int. J. Nanomed. 2014, 9, 51-63.

37. Coulter, J.A.; Jain, S.; Butterworth, K.T.; Taggart, L.E.; Dickson, G.R.; McMahon, S.J.; Hyland, W.B.; Muir, M.F.; Trainor, C.; Hounsell, A.R.; et al. Cell type-dependent uptake, localization, and cytotoxicity of 1.9 nm gold nanoparticles. Int. J. Nanomed. 2012, 7, 2673-2685.

38. Levy, R.; Shaheen, U.; Cesbron, Y.; See, V. Gold nanoparticles delivery in mammalian live cells: A critical review. Nano Rev. 2010, 1, 4889. [CrossRef] [PubMed]

39. Shukla, R.; Bansal, V.; Chaudhary, M.; Basu, A.; Bhonde, R.R.; Sastry, M. Biocompatibility of gold nanoparticles and their endocytotic fate inside the cellular compartment: A microscopic overview. Langmuir 2005, 21, 10644-10654. [CrossRef]

40. Lasagna-Reeves, C.; Gonzalez-Romero, D.; Barria, M.A.; Olmedo, I.; Clos, A.; Sadagopa Ramanujam, V.M.; Urayama, A.; Vergara, L.; Kogan, M.J.; Soto, C. Bioaccumulation and toxicity of gold nanoparticles after repeated administration in mice. Biochem. Biophys. Res. Commun. 2010, 393, 649-655. [CrossRef]

41. Tautzenberger, A.; Kreja, L.; Zeller, A.; Lorenz, S.; Schrezenmeier, H.; Mailander, V.; Landfester, K.; Ignatius, A. Direct and indirect effects of functionalised fluorescence-labelled nanoparticles on human osteoclast formation and activity. Biomaterials 2011, 32, 1706-1714. [CrossRef] 
42. Chaudhari, K.; Pradeep, T. Spatiotemporal mapping of three dimensional rotational dynamics of single ultrasmall gold nanorods. Sci Rep. 2014, 4, 5948. [CrossRef]

43. Zhang, P.; Park, S.; Kang, S.H. Microchip electrophoresis with enhanced dark-field illumination detection for fast separation of native single super-paramagnetic nanoparticles. Bull. Korean Chem. Soc. 2015, 36, 1172-1177.

Sample Availability: Samples of the gold nanoparticles are available from the authors.

(C) 2019 by the authors. Licensee MDPI, Basel, Switzerland. This article is an open access article distributed under the terms and conditions of the Creative Commons Attribution (CC BY) license (http://creativecommons.org/licenses/by/4.0/). 